\title{
Comparison of the Effects of Salbutamol, Epinephrine, and 5\% Inhaled Hypertonic Saline on Infants with Acute Bronchiolitis
}

\author{
Leila Barati (ii) ${ }^{1}$, Seyed Ali Mousavi Khosravi (iD ${ }^{1}$, Safa Ariannejad (iD ${ }^{2}$, Ali Ahani Azari (iD ${ }^{3}$ and Lobat \\ Shahkar (ib) $1,{ }^{*}$ \\ Neonatal and Children's Health Research Center, School of Medicine, Golestan University of Medical Sciences, Gorgan, Iran \\ ${ }^{2}$ Taleghani Hospital, Gorgan, Iran \\ ${ }^{3}$ Musavi Hospital, Gorgan, Iran \\ "Corresponding author: Neonatal and Children's Health Research Center, School of Medicine, Golestan University of Medical Sciences, Gorgan, Iran. Email: \\ lobatshahkar@yahoo.com \\ Received 2021 October 18; Revised 2022 January 26; Accepted 2022 February 01.
}

\begin{abstract}
Background: Bronchiolitis is a lower respiratory tract infection and one of the major health concerns and hospitalization factors in infants.

Objectives: This study aimed to address inconsistencies in treating this disease.

Methods: This study is a double-blind clinical trial investigating the effect of salbutamol, epinephrine, and 5\% inhaled hypertonic saline on treating infants with bronchiolitis referred to the Taleghani Pediatrics Hospital in Gorgan, Iran, during 2019 - 2020 . The clinical results of the treatments and hospitalization stay were also evaluated.

Results: In this study, the study sample encompassed 18 girls and 39 boys. There was no significant difference between the three groups regarding age, gender, parental literacy level, and history of allergies. Salbutamol and epinephrine, in comparison to hypertonic saline, were effective in shortening patients' hospital stay $(\mathrm{P}=0.004)$. Moreover, there was a significant difference between the oxygen saturation of in the patients $48 \mathrm{~h}$ after treatment in the salbutamol and epinephrine groups compared to the saline group $(\mathrm{P}=0.001)$.

Conclusions: In comparison to hypertonic saline, salbutamol and epinephrine can be selected to treat children with acute bronchiolitis since they can shorten hospital stay improve $\mathrm{O}_{2}$ saturation, and decrease treatment costs imposed on the health care system and families.
\end{abstract}

Keywords: Bronchiolitis, Hypertonic Saline, Epinephrine, Salbutamol, Children, Hospital Stay

\section{Background}

Bronchiolitis is a lower respiratory tract infection in infants and one of the factors leading to their hospitalization and morbidity. Respiratory syncytial virus is the most common cause of acute bronchiolitis, accounting for $80 \%$ of cases $(1,2)$. This virus is an RNA virus of the paramyxoviride group and a subgroup of the pneumovirus. The inflammation of the airways in bronchiolitis caused by respiratory syncytial virus is a multicellular process in which macrophages, epithelial cells, cytotoxic T cells, and eosinophils are involved (3). The disease is characterized by the obstruction of the bronchioles due to necrosis of their epithelium, increased mucus secretion, the infiltration of inflammatory cells and edema under the mucosa, and the spasm of the smooth muscles of the bronchial wall. In infants, especially those aged below six months, due to the small diameter of the airways and edema and the inflam- mation of the bronchioles, the virus can lead to respiratory distress (4-6). The disease is more prevalent during the first two years of life. Severe disease is much more common in one to three-month-old infants. About 50 - 80,000 hospitalizations per year in children under one year are attributed to this disease (7).

The complications of the disease include hypoxemia and apnea. Apnea is observed in 10 - 25\% of hospitalized infants, and a ventilation-perfusion mismatch causes hypoxemia. Secondary infection is an uncommon complication reported in $1.2 \%$ of patients (8). No definitive treatment or effective vaccine has been provided for respiratory syncytial virus infection. Fluid therapy, antipyretics, and oxygen are the main treatments of bronchiolitis (9, 10). Because the virus usually causes bronchiolitis, drug treatment is not highly effective. As a suitable nebulizer in patients with mild to moderate bronchiolitis, hypertonic 
saline has decreased the symptoms and the length of hospital stay (6). Recently, treatments such as bronchodilators (eg, salbutamol and epinephrine) have been investigated $(11,12)$. As a selective $\beta 2$ agonist used as a common drug in the treatment of asthma attacks, salbutamol has been examined in many studies to reveal the therapeutic link between salbutamol and bronchiolitis (12). On the other hand, another group of researchers has investigated epinephrine to prove its effectiveness in treating bronchiolitis due to its proven therapeutic capabilities in various cases and the physiology of its effectiveness (11).

\section{Objectives}

Since there is controversy in the treatment of this disease, and relevant information is limited, the effects of three different drugs with different reported effectiveness were investigated in the present study.

\section{Methods}

This study is a double-blind, randomized clinical trial. The study population encompassed all infants aged two months to 24 months, who were admitted to Taleghani Hospital in Gorgan with a diagnosis of acute viral bronchiolitis. The sample size was 65 cases, of whom 57 patients completed the study. The simple random sampling method was used to select the participants; hence, when informed consent was obtained from the eligible patients, the participants in the study were randomly assigned to three groups: (1) salbutamol recipients, (2) hypertonic saline recipients, and (3) inhaled epinephrine recipients. Inclusion criteria were infants aged two months to 24 months with a history of acute viral lower respiratory infection, whose clinical findings were consistent with bronchiolitis. The clinical findings were wheezing, cough, crackle in the lungs with no evidence of bacterial lung infection in the chest X-Ray, fever with $\mathrm{T} \geq 37.8^{\circ} \mathrm{C}$, $\mathrm{RR}>60 / \mathrm{min}, \mathrm{O}_{2}$ Sat percentage $<90$, and severe cyanotic skin color, and bronchiolitis with clinical score 4 - 5 according to PRESS criteria (pediatric respiratory severity score). that the infants' parents were satisfied to participate in the study. Exclusion criteria were drug reaction to salbutamol or epinephrine and hypertonic saline, history of chronic cardiopulmonary disease, history of preterm infants, patients with a history of hospitalization in the first two months, and history of bronchodilator or corticosteroid use before the disease. Regarding the inclusion criteria, the patients were visited by two physicians and included in the study. The patients were randomly divided into three groups and nebulized by Jet Nebulizer from Omeron company. The first group was treated with $2.5 \mathrm{mg}$ of salbutamol nebulizer, $0.5 \mathrm{mg} / \mathrm{kg}$ of epinephrine 1 of 1000 was used for the second group, and the third group received $3 \mathrm{cc}$ of hypertonic $5 \% \mathrm{NaCl}$ solution. At first these drugs were nebulized three times with 30 and 60 minutes interval, then repeated every 4 hours in the first 48 hours of admission.. The patients and the physicians were not informed about the content of the solution of the nebulizer. The patients were assessed 24 and 48 hours later for respiratory rate, pulse rate, and oxygen saturation. The length of hospital stay was also measured and calculated. In this regard, only those days when the patients received medication and oxygen due to bronchiolitis and received parenteral fluids were considered as hospitalization days. The normal range of heart rate was 120 - 160 beats per minute, $\mathrm{t}$ there were 40 - 60 breaths per minute, and the temperature was $36.5-37.8^{\circ} \mathrm{C}$. All patients were kept warm, received supplemental $\mathrm{O}_{2}$ therapy with oxyhood 5 - 7 litter/minute, and were hydrated.

Quantitative variables were described by the mean and standard deviation. First, the normality of the data distribution was checked using the Shapiro-Wilk test to analyze the data. If the data distribution was normal, the analysis of variance (ANOVA) was used. In the absence of parametric tests, nonparametric tests such as Kruskal-Wallis and Mann-Whitney were used. In this study, SPSS software version 18 was used for data analysis, and the significance level was set as $\mathrm{P}=0.05$.

\subsection{Ethical Considerations}

This study was performed after receiving the code of ethics from the ethics committee of the Golestan University of Medical Sciences (Code: IR.GOUMS.REC.1399.222).

The project manager provided necessary explanations about the study and its implementation method to the patients' parents. The participants were reassured they could quit the study in the event of any possible side effects or reluctance to continue the study for any reason. After explaining the research procedures to the parents, they submitted their informed consent.

\section{Results}

A total of 65 infants who met the inclusion criteria participated in this study, of which five infants were excluded due to changes in treatment, three were excluded due to parental request, and 57 cases completed the study. In this study, there were 39 boys and 18 girls, and there was no significant difference between the groups in terms of gender $(\mathrm{P}=0.394)$. The mean age of infants (mean \pm standard deviation (SD)) was $5.61 \pm 3.90$ months. The minimum age was two months, and the maximum was 19 months. 
According to the randomized design criteria, 22 patients in the inhaled salbutamol group, 19 patients in the inhaled epinephrine group, and 16 patients in the 5\% inhaled hypertonic saline group completed the study (Table 1). Moreover, 33 patients (57.9\%) were rural, and 24 patients $(42.1 \%)$ were urban; however, the difference among the three groups in terms of the place of residence was not statistically significant $(\mathrm{P}=0.594)$ (Table 1$)$.

The difference among the three groups in terms of the parents' level of education was not statistically significant $(\mathrm{P}=0.512 ; \mathrm{P}=0.236)$ (Table 1 ).

In this study, 48 patients (84.2\%) were breastfed, and nine patients (15.8\%) were formula-fed. However, the difference among the three groups regarding the type of nutrition was not statistically significant $(\mathrm{P}=0.388)$ (Table 1$)$.

Twelve patients (21.1\%) had a history of asthma or allergies; however, the difference among the three groups was not statistically significant in this regard $(\mathrm{P}=0.644)$ (Table 1).

After 24 and 48 hours of specific treatment in each group, the subjects were evaluated regarding the number of breaths, and it was revealed that the difference among the three groups was not significant $(P=0.300 ; P=0.226)$ (Table 2).

The difference among the three groups in terms of the mean heart rate after 24 and 48 hours was not significant $(\mathrm{P}=0.304 ; \mathrm{P}=0.418)$ (Table 2$)$.

After 24 hours of specific treatment in each group, the subjects were evaluated based on the percentage of oxygen saturation. The mean oxygen saturation percentage between the three groups based on statistical analysis was not significant $(\mathrm{P}=0.141)$; however, after 48 hours of treatment, the mean percentage of oxygen saturation was significantly different among the three groups $(P=0.001)$. The patients in the epinephrine and salbutamol groups had higher saturated oxygen levels than the hypertensive saline group (Table 2).

According to the criteria defined in the study method, the mean length of hospital stay (mean \pm SD) was $3.68 \pm$ 1.38 days with the minimum and maximum of 1 and 7 days for all subjects.

Mean hospital stay was $3.27 \pm 1.27$ days in the salbutamol group with the minimum of 2 and the maximum of 6 days, $3.26 \pm 1.19$ days in epinephrine group with the minimum of 1 and the maximum of 5 days, and $4.5 \pm 1.10$ days in the hypertonic saline with the minimum of 3 and the maximum of 7 days. In this regard, the difference among the three groups was significant $(\mathrm{P}=0.004)$. The patients in epinephrine and salbutamol groups had shorter hospital stays than the hypertonic saline group (Table 2).

\section{Discussion}

Bronchiolitis is one of the most common acute infections of the respiratory tract and lungs during the first years of life. Although the disease is often mild for most healthy infants and young children, it is a major cause of clinical illness and financial pressure on the health care system worldwide (11). Numerous studies have addressed the positive therapeutic effects of bronchiolitis drugs; however, the findings are inconsistent.

The findings of the present study revealed no significant difference between the three groups in terms of heart rate and respiratory rate of patients 24 and 48 hours after the start of specific treatment in each group. Moreover, it was illustrated that the effectiveness of all three drugs in these cases were the same. Further, the improvement of oxygen saturation percentage revealed no significant difference among the three groups after 24 hours of treatment. However, Salbutamol and epinephrine, compared to hypertonic saline, were more effective in decreasing patients' length of hospital stay $(\mathrm{P}=0.004)$. Furthermore, there was a significant difference between the salbutamol and epinephrine groups regarding the oxygen saturation of the patient $48 \mathrm{~h}$ after treatment compared to the saline $\operatorname{group}(\mathrm{P}=0.001)$.

Consistent with the findings of the recent study, other studies in the first 48 hours of treatment reported no significant difference between the drug groups, and the difference in the effectiveness of the treatment groups was determined 48 hours after the start of treatment $(13,14)$. In Hariprakash et al.'s survey, nebulized epinephrine had no superiority over nebulized saline in the treatment of acute bronchiolitis; however, they assessed the intervention only 2 hours after treatment and reported the rate of hospital admission (15). On the other hand, in Anil et al.'s study, there was no significant difference between the outcome variables of the normal saline group with 3\% saline, nebulized salbutamol-normal saline, epinephrine-normal saline in mild bronchiolitis during the two-hour assessment in the emergency room either (1). The inconsistencies in the findings are because of the duration of assessment period and the severity of clinical symptoms.

However, the findings of a recent study provided the evidence of an improvement in oxygen saturation in the epinephrine treatment group compared to other treatment groups. The findings reported by by Langley et al. and Bertrand et al. confirm our findings, suggesting the effectiveness of epinephrine on patients' respiratory parameters in studies on the third and fifth days of treatment (16, 17). However, the statistical population in this clinical trial was limited, and several studies with a high statistical population are required to generalize the findings. 


\begin{tabular}{|c|c|c|c|c|}
\hline Groups & Salbutamol & Epinephrine & Hypertonic Saline 3\% & P-Value \\
\hline Gender & & & & 0.394 \\
\hline Male & $13(59.1)$ & $15(78.9)$ & $11(68.8)$ & \\
\hline Female & $9(40.9)$ & $4(21.1)$ & $5(31.3)$ & \\
\hline Age & & & & 0.354 \\
\hline Mean (mon) & $6.55 \pm 2.6$ & $6.05 \pm 5.15$ & $6.56 \pm 3.56$ & \\
\hline Residency & & & & 0.594 \\
\hline City & $8(36.4)$ & $9(47.3)$ & $7(43.8)$ & \\
\hline Village & $14(63.6)$ & $10(52.7)$ & $9(56.3)$ & \\
\hline Mother's level of Education & & & & 0.512 \\
\hline Illiterate & $1(4.5)$ & $1(5.3)$ & $3(18.8)$ & \\
\hline College & $18(81.8)$ & $15(78.9)$ & $12(75)$ & \\
\hline Academic & $3(13.6)$ & $3(15.8)$ & $1(6.3)$ & \\
\hline Father's level of education & & & & 0.236 \\
\hline Illiterate & $0(0)$ & $0(0)$ & $1(6.3)$ & \\
\hline College & $18(81.8)$ & $18(94.7)$ & $11(68.8)$ & \\
\hline Academic & $4(18.2)$ & $1(5.3)$ & $4(25)$ & \\
\hline Feeding & & & & 0.388 \\
\hline Breast milk & $17(77.3)$ & $16(84.2)$ & $15(93.8)$ & \\
\hline Formula & $5(22.7)$ & $3(15.8)$ & $1(6.3)$ & \\
\hline Allergy history & & & & 0.664 \\
\hline Yes & $6(27.3)$ & $3(15.8)$ & $3(18.8)$ & \\
\hline No & $16(72.7)$ & $16(84.2)$ & $13(81.3)$ & \\
\hline
\end{tabular}

${ }^{a}$ Values are expressed as No. (\%).

Table 2. Respiratory Rate (RR), Pulse Rate (PR), Oxygen Saturation ( $\mathrm{O}_{2}$ Sat), and Duration of Admission in 3 Groups ${ }^{\text {a }}$

\begin{tabular}{|c|c|c|c|c|}
\hline Groups & Salbutamol & Epinephrine & Hypertonic Saline 3\% & P-Value \\
\hline \multicolumn{5}{|l|}{$\mathbf{R R}$ (rate/min) } \\
\hline $24 \mathrm{~h}$ & $26.59 \pm 3.80$ & $29.94 \pm 5.76$ & $28.75 \pm 10.66$ & 0.300 \\
\hline $48 \mathrm{~h}$ & $22.86 \pm 2.93$ & $25.10 \pm 5.72$ & $25.25 \pm 5.79$ & 0.226 \\
\hline \multicolumn{5}{|l|}{ PR (rate/min) } \\
\hline $24 \mathrm{~h}$ & $121.8 \pm 8.53$ & $126 \pm 9.17$ & $123.18 \pm 7.79$ & 0.304 \\
\hline $48 \mathrm{~h}$ & $114.54 \pm 9.45$ & $111.89 \pm 9.42$ & $115.62 \pm 6.19$ & 0.418 \\
\hline \multicolumn{5}{|l|}{$\mathrm{O}_{2}$ sat $(\%)$} \\
\hline $24 \mathrm{~h}$ & $93.54 \pm 2.50$ & $93.42 \pm 1.70$ & $92.18 \pm 2.25$ & 0.141 \\
\hline $48 \mathrm{~h}$ & $96.63 \pm 1.36$ & $97.42 \pm 0.69$ & $95.68 \pm 1.77$ & 0.001 \\
\hline Duration of admission (d) & $3.27 \pm 1.27$ & $3.26 \pm 1.19$ & $4.5 \pm 1.09$ & 0.004 \\
\hline
\end{tabular}

${ }^{\text {a }}$ Values are expressed as mean $\pm \mathrm{SD}$. 
On the other hand, the findings of a recent study on the effectiveness of the studied treatment groups on the length of hospital stay of patients indicate a highly significant effect of salbutamol and epinephrine treatment groups compared to the hypertensive saline treatment group. There was a decrease in the length of hospital stay and a reduction in the length of treatment. However, in a study by Luo et al., there was a statistically significant difference between salbutamol and hypertonic saline in terms of the average length of hospital stay for mild to moderate acute bronchiolitis. Moreover, the hypertonic saline group had a shorter hospital stay (18). In Zamani et al.'s survey, the hypersaline groups had a significantly lower duration of recovery in comparison to the salbutamol group in mild to moderate acute bronchiolitis (3).

However, to compare the findings of other studies correctly away from bias, several parameters, including the difference in the etiology of bronchiolitis in patients in different studies or the vulnerability of the study population due to any other factor such as the type of health system (eg, public vs. private). However, the findings of the present study are supported by several studies, all of which collectively emphasize the effectiveness of salbutamol and epinephrine treatment in reducing hospital stays $(1,13,14$, 16, 19-21).

Although limited studies are in the opposite spectrum and, based on their findings, support the ineffectiveness of salbutamol and epinephrine in reducing patients' length of hospital stay $(22,23)$.

Nevertheless, systematic studies on this field show a clear and significant improvement in patients' condition and clinical symptoms from the third day onwards and the possibility of no need for treatment. Patients with bronchiolitis are also likely to be hospitalized for more than four days if they use no epinephrine in their treatment regimen $(11,12)$.

\subsection{Conclusions}

According to the present study's findings, salbutamol and epinephrine can be considered suitable options for the treatment of children with bronchiolitis since they can reduce hospitalization, improve clinical symptoms more quickly, and reduce the cost of treatment imposed on the health system.

\subsection{Limitations}

Some parents were unwilling to continue treatment as suchthey were excluded from the study.

\subsection{Suggestions}

Examining larger sample over a longer period by designing more study groups and prescribing drugs in combination and investigating other parameters would provide more effective results. Moreover, studies in several educational and medical centers will undoubtedly provide more generalizable findings.

\section{Footnotes}

Authors' Contribution: Study concept and design: L.SH., L. B., S. A. M., S. A.; Analysis and interpretation of data: L. SH., L. B., S. A. M., and A. A.; Drafting of the manuscript: L. SH., L. B., S. A. M., and A. A.; Critical revision of the manuscript for important intellectual content: L. SH., L. B., S. A. M., S. A.; Statistical analysis: L. SH., L. B., S. A. M., and A. A.

Clinical Trial Registration Code: IRCT20201101049210N1. Conflict of Interests: There is no conflict of interests.

Data Reproducibility: The data presented in this study are openly available in one of the repositories or will be available on request from the corresponding author by this journal representative at any time during submission or after publication. Otherwise, all consequences of possible withdrawal or future retraction will be with the corresponding author.

Ethical Approval: IR.GOUMS.REC.1399.222.

Funding/Support: Neonatal and Children's Health Research Center funded this study.

Informed Consent: Written informed consent was obtained from all patients.

\section{References}

1. Anil AB, Anil M, Saglam AB, Cetin N, Bal A, Aksu N. High volume normal saline alone is as effective as nebulized salbutamol-normal saline, epinephrine-normal saline, and $3 \%$ saline in mild bronchiolitis. Pediatr Pulmonol. 2010;45(1):41-7. doi: 10.1002/ppul.21108. [PubMed: 19953579].

2. Varmaghani M, Farzadfar F, Sharifi F, Rashidian A, Moin M, MoradiLakeh M, et al. Prevalence of asthma, COPD, and chronic bronchitis in Iran: a systematic review and meta-analysis. Iran J Allergy Asthma Immunol. 2016;15(2):93-104.

3. Zamani M, Movahhedi M, Nourbakhsh SM, Ganji F, Rafieian-Kopaei M, Mobasheri M, et al. Therapeutic effects of Ventolin versus hypertonic saline 3\% for acute bronchiolitis in children. Med J Islam Repub Iran. 2015;29:212.

4. Ralston SL, Lieberthal AS, Meissner HC, Alverson BK, Baley JE, Gadomski AM, et al. Clinical practice guideline: the diagnosis, management, and prevention of bronchiolitis. Pediatrics. 2014;134(5):e1474-502. doi: 10.1542/peds.2014-2742. [PubMed: 25349312].

5. Rabago D, Pasic T, Zgierska A, Mundt M, Barrett B, Maberry R. The efficacy of hypertonic saline nasal irrigation for chronic sinonasal symptoms. Otolaryngol Head Neck Surg. 2005;133(1):3-8. doi: 10.1016/j.otohns.2005.03.002. [PubMed:16025044]. 
6. Zhang L, Mendoza-Sassi RA, Wainwright C, Klassen TP. Nebulised hypertonic saline solution for acute bronchiolitis in infants. Cochrane Database Syst Rev. 2017;12. CD006458. doi: 10.1002/14651858.CD006458.pub4. [PubMed: 29265171]. [PubMed Central: PMC6485976].

7. Hartling L, Fernandes RM, Bialy L, Milne A, Johnson D, Plint A, et al. Steroids and bronchodilators for acute bronchiolitis in the first two years of life: systematic review and meta-analysis. BMJ. 2011;342:d1714. doi: 10.1136/bmj.d1714. [PubMed: 21471175]. [PubMed Central: PMC3071611].

8. Lieberthal AS, Bauchner H, Hall CB, Johnson DW, Kotagal U, Light MJ, et al. Diagnosis and management of bronchiolitis. Pediatrics; 2006.19 p.

9. Hall CB. Respiratory syncytial virus and parainfluenza virus. $N$ Engl J Med. 2001;344(25):1917-28. doi: 10.1056/NEJM200106213442507. [PubMed: 11419430].

10. Fernandes RM, Bialy LM, Vandermeer B, Tjosvold L, Plint AC, Patel H, et al. Glucocorticoids for acute viral bronchiolitis in infants and young children. Cochrane Database of Systematic Reviews. Cochrane Library; 2010. doi: 10.1002/14651858.CD004878.pub3.

11. Hartling L, Bialy LM, Vandermeer B, Tjosvold L, Johnson DW, Plint AC, et al. Epinephrine for bronchiolitis. Cochrane Database Syst Rev. 2011;(6). CD003123. doi: 10.1002/14651858.CD003123.pub3. [PubMed: 21678340].

12. Cai Z, Lin Y, Liang J. Efficacy of salbutamol in the treatment of infants with bronchiolitis: A meta-analysis of 13 studies. Medicine (Baltimore). 2020;99(4). e18657. doi: 10.1097/MD.0000000000018657. [PubMed: 31977855]. [PubMed Central: PMC7004745].

13. Flores-Gonzalez JC, Matamala-Morillo MA, Rodriguez-Campoy P, Perez-Guerrero JJ, Serrano-Moyano B, Comino-Vazquez P, et al. Epinephrine Improves the Efficacy of Nebulized Hypertonic Saline in Moderate Bronchiolitis: A Randomised Clinical Trial. PLoS One. 2015;10(11). e0142847. doi: 10.1371/journal.pone.0142847. [PubMed: 26575036]. [PubMed Central: PMC4648584].

14. American Academy of Pediatrics. Bronchiolitis in Hospital: Nebulized
Hypertonic Saline/Salbutamol? AAP Grand Rounds. 2010;23(2):16. doi: 10.1542/gr.23-2-16.

15. Hariprakash S, Alexander J, Carroll W, Ramesh P, Randell T, Turnbull $\mathrm{F}$, et al. Randomized controlled trial of nebulized adrenaline in acute bronchiolitis. Pediatr Allergy Immunol. 2003;14(2):134-9. doi: 10.1034/j.1399-3038.2003.00014.x. [PubMed: 12675760].

16. Langley JM, Smith MB, LeBlanc JC, Joudrey H, Ojah CR, Pianosi P. Racemic epinephrine compared to salbutamol in hospitalized young children with bronchiolitis; a randomized controlled clinical trial [ISRCTN46561076]. BMC Pediatr. 2005;5(1):1-7. doi: 10.1186/1471-2431-5-7. [PubMed: 15876347]. [PubMed Central: PMC1142326].

17. Bertrand P, Aranibar H, Castro E, Sanchez I. Efficacy of nebulized epinephrine versus salbutamol in hospitalized infants with bronchiolitis. Pediatr Pulmonol. 2001;31(4):284-8. doi: 10.1002/ppul.1040. [PubMed: 11288210].

18. Luo Z, Liu E, Luo J, Li S, Zeng F, Yang X, et al. Nebulized hypertonic saline/salbutamol solution treatment in hospitalized children with mild to moderate bronchiolitis. Pediatr Int. 2010;52(2):199-202. doi: 10.1111/j.1442-200X.2009.02941.x. [PubMed:19674354].

19. Ziaei Kajbaf T, Taheri M, Gheysari A. [Comparison of Inhalation Epinephrine with Salbutamol in the Treatment of Infants with Acute Bronchiolitis]. Sci Med J. 2008;7(2):7-9. Persian.

20. Tal G, Cesar K, Oron A, Houri S, Ballin A, Mandelberg A. Hypertonic saline/epinephrine treatment in hospitalized infants with viral bronchiolitis reduces hospitalization stay: 2 years experience. Imaj Ramat Gan. 2006;8(3):169.

21. Everard ML. Acute bronchiolitis and croup. Pediatr Clin North Am. 2009;56(1):119-33. x-xi. doi: 10.1016/j.pcl.2008.10.007. [PubMed: 19135584].

22. Bilan N, Seyad Sadri N. [Clinical study of salbutamol in the treatment of bronchiolitis]. Tabriz Univ Med Sci. 2007;29(1):27-9. Persian.

23. Sanchez I. A multicenter, randomized, double-blind, controlled trial of nebulized epinephrine in infants with acute bronciolitis. J Pediatr. 2004;144(1):136-7. doi:10.1016/j.jpeds.2003.10.027. 